\title{
TEORIA SOCIAL E CRISE ECOLÓGICA CONTRIBUIÇÕES E ATUAIS IMPASSES DA TEORIA MARXISTA FRENTE À QUESTÃO AMBIENTAL
}

\author{
TEORÍA SOCIAL Y CRISIS ECOLÓGICA \\ APORTACIONES Y ACTUALES IMPASSES DE LA TEORÍA MARXISTA ANTE \\ LA CUESTIÓN AMBIENTAL
}

\author{
SOCIAL THEORY AND ECOLOGICAL CRISIS \\ CONTRIBUTION AND PRESENT DEADLOCK OF MARXIST THEORY \\ REGARDING THE ENVIRONMENTAL ISSUE
}

\author{
João Júlio Vitral AMARO1
}

RESUMO: As ciências sociais se defrontam com a prodigalidade dos resultados das chamadas ciências da natureza quando nos países industrializados emerge a questão ecológica. Tomando parte da história do pensamento econômico, como caso exemplar para ilustrar os impasses da teoria social, são abordados alguns aspectos do pensamento de Karl Marx nos quais se mostra que a "natureza" não constrange o desenvolvimento da forma social que ele examina. A questão também é tratada a partir de outras contribuições oriundas da tradição marxistas, como a de Elmar Altvater, na qual a "natureza", observada fundamentalmente a partir da Segunda Lei da Termodinâmica, poderá fixar os limites da ordem social capitalista.

Palavras-chave: teoria social, teoria econômica, política ambiental

RESUMEN: Las ciencias sociales se enfrentan con la prodigalidad de los resultados de las llamadas ciencias de la naturaleza cuando en los países industrializados emerge la cuestión ecológica. En este estudio se toma parte de la historia del pensamiento económico, como caso ejemplar para ilustrar los impasses de la teoría social, y se enfocan algunos aspectos del pensamiento de Karl Marx en los que se muestra que la «naturaleza» no constriñe el desarrollo de la forma social examinada por él. Se trata también la cuestión a partir de otras aportaciones provenientes de la tradición marxista, como la de Elmar Altvater, en la cual la «naturaleza», observada fundamentalmente a partir de la Segunda Ley de la Termodinámica, podrá fijar los límites del orden social capitalista.

Palabras clave: teoría social, teoría económica, política ambiental

\footnotetext{
1 Prof. Dr. na Escola de Arquitetura, Universidade Federal de Minas Gerais (UFMG). Doutorado no Departamento (Fachbereich) Umwelt und Gesellschaft - Technische Universitaet Berlin, Alemanha. Msc. em Economia (UFMG), Teoria Econômica. Especialização em Planejamento Habitacional, Faculdade de Arquitetura da UNB. Graduação em Arquitetura (UFMG). Experiência na área de Economia, com ênfase em Economia Ambiental e Urbana, atua nos temas: meio ambiente, metodologia da análise ambiental, paisagem urbana, planejamento, avaliação de curso superior e teoria de sistemas. juliovitral@yahoo.com.br
} 
ABSTRACT: Social Sciences face themselves with the prodigality of the so-called Natural Sciences when in the industrialised countries the ecological question emerges. Taking part in the economic thought, as a model case to highlight the deadlocks in social theory, a number of thoughts from Karl Marx are addressed which show that "nature" does not constrain development in social form in the way he examines. This issue is also dealt wih in different contributions based in the Marxist tradition, as the one from Elmar Altvater, in which "nature", observed mainly form the Second Law of Themodynamics, may determine limits of social capitalist order.

Keywords: social theory, economic theory, environmental policy

\section{INTRODUÇÃO}

Explicar como as coisas da natureza, ou melhor, as coisas não criadas ou não elaboradas pelos homens têm um preço e são, assim, trocáveis no mercado, foi uma das ocupações da Economia Política clássica e ainda é hoje fonte de controvérsias. A questão deixa de ser uma simples discussão sobre a história da formação do pensamento econômico e passa a ser fundamental nas discussões atuais sobre políticas ambientais; quer dizer, da elucidação desta questão se espera o suporte teórico necessário para as medidas tributárias relacionadas com a exploração agrícola ou mineral, de ressarcimento dos danos ambientais, de estimativas do estoque futuro dos bens naturais e da capacidade de substituição dos chamados bens naturais.

\section{DISCUSSÃO}

A discussão deve se iniciar pela primeira questão levantada pelos primeiros que fizeram a idade heróica da economia: qual o fundamento dos preços? Algumas coisas custam mais caro do que outras porque são mais escassas ou porque demandam mais trabalho? Às primeiras perguntas foram apresentados argumentos para demonstrar que o valor, fundamento dos preços, relaciona-se com quantidades de trabalho incorporadas em uma mercadoria. $\mathrm{Na}$ obra de Marx há uma abordagem da natureza que envolve uma dimensão teórica inapreensível se a consideração sobre os valores fica restrita à consideração deles como quantum de trabalho tão somente. Vê-se ali que expressões como "matéria natural" (Naturstoff), 
"substrato material" (materielle Substrat) ou simplesmente "natureza" (Natur) são expressões equivalentes, quando Marx se refere ao que não é "filtrado pelo trabalho". A "natureza", por ser a provedora originária da matéria que será objeto de trabalho, é o pressuposto da atividade produtiva humana. É desse modo que os dois elementos que se combinam nos valores de uso - o trabalho e o substrato natural - são tratados por Marx, respectivamente, como atividade formativa e componente material (Marx, 1977, p.239, v.I).

A dupla realidade da mercadoria como "valor de uso" e "valor" não é, de acordo com Marx, arbitrária, não simplesmente pensada, mas traduz o fato de uma mercadoria ser objeto da satisfação humana (com suas características naturais) e produto do trabalho (e, portanto, ser trocada no mercado por um equivalente a outro quantum de trabalho no mercado). $\mathrm{O}$ "valor" da mercadoria se expressa no "valor de troca", ou seja, em uma outra mercadoria equivalente em quantum de trabalho.

Marx, ao apontar que os valores de uso são a combinação desses dois elementos - a substância natural e o trabalho - não tinha por perspectiva a decantação deles a partir dos valores de uso particulares. Isto é, não se pode separar in abstracto o que, por um lado, remonta ao trabalho e o que é, nos valores de uso, a matéria fornecida pela natureza. Vale dizer, em que relação quantitativa e qualitativa se encontram a atividade produtiva humana e a substância natural é algo que não se coloca quando Marx considera os valores de uso. Qualquer que tenha sido o nível de complexidade do processo produtivo do qual um valor de uso é resultado, a substância natural trabalhada continua sendo parte do mundo sensível. No resultado reificado do trabalho (ou seja, na mercadoria) esconde-se o movimento que o produziu, e, na medida em que esse resultado se incorpora a processos mais amplos, degradase novamente à coisa sensível, ao "modo de existência material" (sinnliche Existenzweise), ao objeto, que ao ser consumido, impõe ainda as suas determinações naturais. Tais determinações impostas pela natureza deverão encontrar expressão como categorias econômicas (Marx, 1981, p.163, v.II).

Observando mais de perto essa polarização constitutiva dos valores de uso é possível relacionar a natureza com a produção no plano material e o trabalho com a produção no plano formal onde, então, as leis naturais persistem sob a atividade formativa do trabalho. Aqui é interessante apontar a aproximação possível entre os conceitos aristotélicos de "forma" e "matéria". Forma é o principio de ordem, é a escultura que preexiste na cabeça do escultor, matéria é o substrato passivo, o bloco de mármore: princípio masculino e principio feminino. De fato, nesse contexto, ocorre a Marx lembrar de Willian Petty, para quem a "terra é a mãe e 
o trabalho é o pai”. A matéria natural, por possuir suas próprias leis - e os propósitos humanos se realizam através dos processos naturais - faz com que os conteúdos da atividade humana não sejam apenas sócio-históricos, mas também limitados pela própria estrutura material (Marx:1981.v.I.pg.51).

Lembrando que Karl Marx tem como propósito reconstituir os movimentos essenciais do capital, sua ênfase é a "reificação" ou o processo de "desligamento" a que somos levados na imersão das relações capitalistas. Assim é que, independente de os valores de uso terem sido produzidos ou não pela intervenção humana, pelo trabalho, eles são situados na teoria de acordo com o pretenso poder autônomo que adquirem. Eles adquirem o poder de coisas que se defrontam com os homens como uma existência independente, como a da "substância natural" ainda não conformada pelo trabalho. Marx observa que o trabalho materializado dos operários aparece como "uma potência que se sobrepõe àqueles que o produziram". O mundo das mercadorias aparece como se proviesse da "coisa"-capital, o aumento dos lucros, da produtividade etc., e finalmente, o valor aparece como propriedade natural das coisas.

O capital aparece autonomizado, se disfarça nos "poderes das coisas" (sachliche Mächte). Na aparência da vida econômica, são as coisas que se erigem como poder de dominação sobre os agentes produtivos. Desse modo, o capital, a terra e o trabalho encontram, na superfície da vida econômica, a correspondente expressão da autonomia que eles adquirem. Para Marx, o valor da terra é uma "expressão irracional", pois "a terra não é criada socialmente". Mas essa "expressão imaginária", esta abstração, corresponde, no entanto, a relações materiais veiculadas pelo capital; vale dizer, corresponde a relações de produção reais. Apenas assim, a terra, nessa "inversão mistificadora", encontra "legitimidade" como fonte de ganhos para seus proprietários: “os vínculos de produção recíprocos convertidos em autônomos com relação aos indivíduos se apresentam também de maneira tal que os indivíduos são agora dominados por abstrações” (Marx, 1977, p. 92, v.I).

Desse modo, Marx considera que as categorias da economia política, antes de serem abstrações pensadas por quem analisa a sociedade capitalista, devem ser expressões teóricas da abstração real, presente na vida econômica. Aqui está implicada uma distinção crucial que foi desconsiderada pelos clássicos: uma coisa é a dimensão invisível, essencial, onde se escondem as determinações do valor, mais-valia, taxa de mais-valia; outra coisa é a superfície da vida econômica na qual lucro, taxa de lucro etc. são formas de manifestação, formas fenomênicas (Erscheinunqsformen) de relações essenciais. Essas formas de manifestação - o "mundo dos fenômenos" (Erscheinungswelt) - compõem a "realidade efetiva" (Wirklichkeit), 
o lugar exclusivo da realização dos valores ou mais-valia; enfim, das relações essenciais. São conceitos de Hegel que Marx traz para a sua exposição. Para Hegel, a aparência, ou o mundo das aparências, não é uma mera cópia da realidade; mas a aparência é realização da essência, e a essência, por sua vez, se faz realidade ou realidade efetiva (Wirklichkeit) na aparência (Marx, 1981, p. 53, v.III).

A teoria da renda da terra n`O Capital de Marx, assim como todo o conjunto da obra econômica marxiana, está permeada por representações sobre a natureza. É possível apontar e alguns autores já o fizeram - um "conceito de natureza" na tessitura teórica do pensamento de Karl Marx. Não se pretende aqui o rastreamento de uma "filosofia da natureza" em Marx, mas o rigoroso crítico da Economia Política que, em uma de suas objeções aos economistas, faz notar que estes, ao se orientarem por um "brutal interesse" no estudo do consumo social dos bens naturais, deixam de ver como se imiscuem as propriedades da natureza com as determinações econômicas.

David Ricardo examinou a lei econômica relacionada com a fertilidade e o preço da terra. No entanto, Marx observa, esse economista considera apenas a fertilidade "originária", como "força primitiva". A fertilidade na teoria marxiana tanto pode ser a da terra considerada como fonte original de víveres e meios de subsistência já prontos para o uso quanto a que é introduzida pela intervenção humana; quer dizer, a fertilidade é tanto dada pela natureza quanto introduzida pelos fertilizantes, por exemplo. Desse modo, diz Marx, a fertilidade, embora propriedade objetiva do solo, implica sempre uma relação econômica, uma relação com o estágio do desenvolvimento das forças produtivas. Dependerá, portanto, do desenvolvimento químico e do desenvolvimento mecânico da agricultura o grau em que cada economia deve contar com os atributos originários da terra.

Marx reconhece que David Ricardo tem o mérito de propor a teoria da renda da terra vinculada com a teoria do valor. De fato, Ricardo recusa a suposição de Adam Smith de que a lei que regula o valor pelo quantum de trabalho é modificada pela propriedade da terra; quer dizer pela propriedade privada dos atributos naturais e pelos consequentes rendimentos auferidos pelos proprietários fundiários. Projetando a preocupação hodierna sobre o "consumo" da natureza, podemos dizer que os clássicos da economia política promoviam o debate sobre a apropriação privada dos bens da natureza; quer dizer, o capitalismo nascente, por meio de seus teóricos, antecipa questões que apenas agora, no aprofundamento desse específico modo de produção, podem ser examinadas em toda sua extensão. 
Ricardo, como Marx reconheceu, tem o mérito de esboçar a lei de formação da renda fundiária ao apontar que mesmo as glebas onde não se inverteu trabalho, têm preços ocasionados pela regularidade de determinações econômicas específicas. Assim, Marx insiste no fato de que, como todas as determinações econômicas, as determinações que regem a renda e o preço da terra - que são enfim, os preços da "natureza" - são fundadas na lei do valor; isto é, são as determinações dadas pelo próprio modo de produção capitalista que fazem com que atributos naturais tenham de se expressar como preço e não imediatamente como quantum de fertilidade.

As sociedades humanas já conheceram articulações derivadas do fato de a terra ser a principal fonte de riqueza onde as relações sociais se organizavam a partir da propriedade da terra. Nas sociedades capitalistas, não predomina a propriedade da terra, nelas o capital é a "potência econômica" que tudo domina. Mas, mesmo assim, o monopólio da propriedade fundiária permanece como um pressuposto histórico e constante fundamento do modo de produção capitalista. Ricardo, em um de seus argumentos contra a propriedade fundiária, supõe que a posse da terra, por impedir que todas as terras potencialmente agricultáveis sejam utilizadas, levaria a uma menor produção relativa da agricultura. Marx, contra essa suposição, observa que se a terra fosse disponível a todos, seria impossível a formação de uma camada da população disponível ao capital, faltaria o trabalho assalariado - "o elemento principal para a formação do capital" (Marx, 1975, p.37, v.II).

A renda capitalista da terra é o valor de troca pelo valor de uso monopolizado da terra; quer dizer, é a expressão em dinheiro pela apropriação privada de parte da natureza. Assim, o estudo dessa forma de renda implica considerar a natureza ou a fertilidade e outros atributos naturais da superfície da terra sob a dominação do capital. A natureza é o pressuposto da atividade produtiva humana e as propriedades naturais das coisas fazem valer suas determinações quando a natureza é apropriada socialmente. Quando a forma social da apropriação da natureza tem por elemento dominante o capital, a natureza, embora preceda geneticamente a produção social em geral, cede lugar, como princípio explicativo, ao elemento dominante. Desse modo, as determinações da natureza não são consideradas por Marx de forma genérica, como categorias a-históricas e nem tampouco como neutras em relação às "necessidades" do capital; quer dizer, as leis da Natureza, de modo algum, podem ser derrogadas. O que pode se modificar em condições históricas diferentes é tão somente a forma sob a qual tais leis se impõem. 
Marx considera possível que, na agricultura, o aumento da força produtiva social “apenas compense ou nem sequer compense a diminuição da força natural”. Vale dizer, a produtividade social, que significa o aumento nos outros ramos produtivos do número de unidades produzidas com determinado quantum de valor, atua na agricultura para repor a perda da fertilidade natural da terra. $\mathrm{O}$ decréscimo da quantidade de produtos que a terra, pelas suas propriedades naturais, é capaz de produzir se evidencia no decorrer do tempo, fazendo com que o capital constante aplicado na agricultura não se traduza em um aumento da produtividade. (Marx, 1975, p.16, 79, v. II).

Marx observa que, no decorrer do desenvolvimento capitalista, a produtividade na agricultura não se desenvolveu com a mesma velocidade que na indústria, quer dizer, o trabalho na agricultura tornou-se relativamente menos produtivo que o trabalho industrial. Este é um fenômeno histórico que não necessariamente tem razão em se manter e que Ricardo, segundo Marx, converteu em lei eterna. O fato de a agricultura sob o capitalismo, embora mais produtiva em termos absolutos, se tornar relativamente menos produtiva, leva a que o produto agrícola tenha um maior valor relativo se comparado com os produtos industriais. Essa elevação relativa dos valores dos produtos agrícolas eleva também a renda fundiária, mostrando assim uma "contradição inerente" à produção capitalista: a agricultura, por desenvolver a produtividade com menor velocidade, permite ao proprietário fundiário maior apropriação da renda. Isso quer dizer que paradoxalmente os latifundiários se beneficiam da progressiva perda daquilo que lhes é dado possuir pela regulamentação jurídica da propriedade. Eles se apropriam legalmente das forças da natureza e, contraditoriamente, ganham mais com a perda da capacidade natural da terra em produzir. É interessante observar, no âmbito do estudo da Renda Absoluta (onde n` $O$ Capital é tratada a forma de renda derivada das diferenças de produtividade entre indústria e agricultura) que Marx chega a conclusões tão "pessimistas" e tão condenatórias à propriedade fundiária quanto as de Ricardo. Nos capítulos sobre a Renda Diferencial, no entanto, Marx vê, depois de cinquenta anos das observações de Ricardo, o avanço da tecnologia sobre a agricultura, sobretudo como consequência da aplicação de fertilizantes químicos, a partir das pesquisas de Justus Liebig (Marx, 1981, p. 778, 787, v.III).

Ricardo que, de acordo com Marx, pretendeu denunciar a imposição da propriedade fundiária como forma específica do consumo dos bens naturais, não consegue fundamentar teoricamente sua posição contrária aos rentistas. Marx considera que Ricardo, por não ter identificado a formação da Renda Absoluta, deixou de reconhecer o "efeito econômico" da 
propriedade do solo. Mas a maior diferença que entre ambos a teoria da Renda Absoluta vem tornar patente é que Ricardo propõe uma teoria que, embora não sendo assumidamente uma teoria "físiológica" do valor, deixa lugar a uma "naturalização" da investigação sobre o valor: Ricardo procura a "coisa" valor, quer em suas mãos, como todo empirismo, a expressão tangível da teoria. Ao fazer da "medida invariável do valor" a sua pedra filosofal, Ricardo apreende apenas de modo incompleto a forma social subjacente ao valor. Ironicamente a teoria ricardiana transforma o valor em "coisa", em "natureza"; e, por isso mesmo, deixa de apreender o consumo dos bens naturais quando da submissão da natureza às relações sociais determinadas pelo capital.

Vale lembrar aqui das consequências da teoria de Ricardo para o alvorecer do pensamento socialista moderno quando, então, Owen e seus seguidores propõem os "certificados de trabalho" como meio de assegurar a justa remuneração dos trabalhadores ao fazer desses certificados a expressão exata do quantum de trabalho. Que esses "ricardianos de esquerda" se iludiam foi demonstrado por Marx em suas considerações sobre as oscilações de valor de qualquer meio que também pudesse servir de moeda (Marx, 1981, p.109, v.I).

O pensamento econômico que prevalece após a idade heróica da Economia Política é marcado pela recusa da teoria do valor-trabalho. São outras as questões colocadas pela economia mainstream para abordar em termos mais teóricos a questão ambiental. Herdeira dos neoclássicos, os modelos utilizados para tentar reproduzir conceitualmente a realidade econômica pecam por adotar princípios explicativos que pouco contribuem para atenuar as agressões ao meio ambiente. Para as atuais vertentes teóricas hegemônicas é sempre pressuposta a substituição entre bens produzidos pelo homem (capital) e bens naturais, ao mesmo tempo em que se confia à inovação tecnológica a capacidade de sempre oferecer uma resposta à escassez dos recursos naturais. Como conseqüência, essas teorias afirmam a possibilidade de sempre se manter os atuais modelos de crescimento econômico, mesmo com recursos escassos, na condição de que esses possam ser substituídos pelo capital, seja pela inovação tecnológica, seja pela reciclagem completa. Essa perfeita substituição de fatores comumente pressuposta pelos neoclássicos revela uma concepção subjacente de "reversibilidade" da qual nem Marx nem os clássicos da Economia Política teriam escapado já que estão envolvidas aí representações que o senso comum aceita e que, dado o predomínio das representações sobre o tempo da física clássica, são difíceis de serem neutralizados (Georgescu-Roegen,1999). 
Para Georgescu-Roegen, é surpreendente que a teoria neoclássica tenha adotado o modelo mecanicista quando a mecânica clássica não tinha mais o domínio absoluto na física. A evidência dos modelos mecanicistas é a representação, comum nos livros de economia, do processo econômico como um diagrama circular, um movimento pendular entre a produção e o consumo em um sistema completamente fechado. Georgescu-Roegen, físico e economista, convida a um olhar crítico aos paradigmas da economia a partir da segunda lei da termodinâmica, já que este princípio tem uma extensão teórica e prática que vai muito além do domínio das máquinas a vapor e muito tem a indicar sobre o consumo energético nas sociedades industriais. O segundo princípio da termodinâmica introduz o conceito de "qualidade" de energia, uma medida da capacidade de um sistema de transformar o calor em energia mecânica. Esta segunda lei foi estabelecida quando Clausius distinguiu processos reversíveis de processos irreversíveis, introduzindo o conceito de "entropia": uma grandeza que aumenta com a dissipação e atinge o seu valor máximo quando todo o potencial de executar trabalho está esgotado. De acordo com essa versão da segunda lei, num processo reversível a variação de entropia é nula, ao passo que nos processos irreversíveis a entropia sempre aumenta (Coveney, 1993, p.130). Com o enunciado do segundo princípio mostra-se que o problema com o qual a humanidade se confronta não é o da conservação da energia, mas o da conservação de certa qualidade de seu dote energético, ou seja, de sua capacidade de fornecer trabalho útil (Hémery, 1993, p.17).

A energia existe em dois estados qualitativos: a energia disponível e a energia não disponível. Essa distinção, assumidamente antropomórfica, diz que a energia química contida em um pedaço de carvão, por exemplo, é energia disponível porque o homem pode transformá-la em calor e assim em trabalho mecânico. A imensa energia calorífica do mar é energia não disponível. A energia disponível implica uma estrutura ordenada. Desse modo, pode-se dizer que a entropia se define também como uma medida de ordem/desordem. De acordo com Georgescu-Roegen, para quem os princípios da termodinâmica devem se aplicar na consideração econômica da transformação material, uma lâmina de cobre apresenta menor entropia que o mineral que o produziu (Georgescu-Roegen, 1989, p. 63). Para este autor, a dissipação ou degradação da matéria/energia (dos elementos dispostos pela natureza) segue uma rota de irreversibilidade que é acelerada pela produção humana: uma folha de papel apresenta uma entropia mais baixa do que a massa de celulose, com a qual a sua produção se iniciou. Esse aumento de ordem (a baixa entropia da folha de papel) só foi possível porque em algum lugar a entropia (desordem) aumentou na forma de dispersão de energia dos 
trabalhadores e das máquinas e de dejetos líquidos, de gases na atmosfera. A constatação de que a entropia proporciona uma "flecha do tempo" explícita - ou seja, a entropia crescente coincide com o movimento do tempo para frente (Coveney, 1993, p. 130) - vem fazer com que os modelos reversíveis da economia sejam questionados como modelos que possam apreender a degradação ou dissipação da matéria-energia presentes em todas dimensões do processo econômico em geral (produção, transporte, consumo etc.).

A partir da perspectiva adotada por Georgescu-Roegen, Elmar Altvater mostra que, se considerada pela lei da termodinâmica, "a produção não é nada mais que transformação de energia e matéria, pela qual um input de que nós dispomos se transforma em um output de que nós necessitamos" (Altvater, 1987), para os agentes econômicos (empresários, capitalistas) essa transformação é indiferente, desde que possa ser criado o excedente que brota do processo de transformação. Entenda-se excedente aqui como categoria econômica; ou seja, como acréscimo ao capital adiantado. O processo de produção é, portanto, o processo de trabalho, no qual a transformação de matéria e energia age segundo as leis da natureza, e o processo (social) de valorização, cujo percurso faz gerar um acréscimo ao capital (Altvater, 1987). Considerando essas duas lógicas superpostas, Altvater aponta a dificuldade de se "ecologizar" a economia. Considerando que há "igualdade entre inputs e outputs na termodinâmica (ecologia) e produção de excedente na economia" observa-se então uma dificuldade intransponível e "esta contradição estrutura as relações entre economia e ecologia no modo de produção capitalista" (Altvater, 1987). De fato, os materiais transformados em valor de uso (matéria transformada e degradada de acordo com a termodinâmica) são, ao mesmo tempo, valores de troca. Isso quer dizer que eles (os valores de troca, ou matéria transformada) são subssumidos à forma-valor e, com isso, à forma-dinheiro. Submetida ao fluxo das trocas mercantis, toda transformação qualitativa de matéria-energia (com todos os percalços impostos pelo princípio da entropia) é trazida para uma unidade igual de medida (o dinheiro) e "a partir daí só podem se distinguir quantitativamente" (Altvater:1987). Para a mercadoria, submetida à forma-valor, fica perdida, na representação social, a natureza modificada da qual ela se origina.

Como foi mostrado atrás, Karl Marx critica a iniciativa dos primeiros representantes modernos do pensamento socialista em propor uma moeda que representasse imediatamente a quantidade de trabalho (os "certificados de trabalho"). O ataque a Owen faz parte da crítica que Marx faz de Ricardo, em particular, e do empirismo dos economistas, em geral, e, assim, numa consideração mais ampla, pode também ser trazida para refletir sobre a questão 
ecológica. O núcleo conceitual no qual se baseia a crítica aos “certificados de trabalho" é a teoria monetária de Marx da qual podemos também concluir, como Altvater, que toda transformação qualitativa de matéria e energia gasta nos processos econômicos só podem se expressar quantitativamente pela única unidade de medida possível no capitalismo, o dinheiro. Desse modo, ao depararmos com propostas de criação de uma "moeda" que representaria o quantum energético de uma mercadoria no intuito de trazer para a realidade social as consequências do processo natural implícito na produção material (capitalista), não poderia deixar de nos ocorrer a critica de Marx à “coisa"-valor dos economistas.

\section{CONSIDERAÇÕES}

A partir da critica de Marx aos pensadores sociais de seu tempo, é possível abordar a questão ecológica nas representações e práticas sociais. Grande parte das representações que a sociedade faz de si mesma baseia-se no predomínio do discurso da economia: a economia é o grande reservatório semântico das sociedades que avançaram mais nos processos de transformação material e produção de resíduos (industrialização). No entanto, como mostra Georgescu-Roegen, a economia mainstream é tributária de modelos que desconsideram tempo e espaço; e, por isso, são deficitários exatamente na possibilidade de apreensão da transformação material, física, nas sociedades industrializadas. Em seu texto seminal (“Ökologische und Ökonomische Modalitäten von Zeit und Raum”) Altvater (1987) apresenta a base teórica que vai orientar seus escritos posteriores, afirmando, logo de início, que a economia "sem tempo e sem espaço" existe apenas nos modelos neoclássicos da "economia pura"; e como para confirmar, logo a seguir, a fonte inspiradora para suas reflexões, nosso autor cita Georgescu-Roegen: "the neoclassical mode of representing the production function ignores the time factor". São enormes as consequiências desse pensamento que se expressa em frases tão curtas.

Trazer o aparato conceitual elaborado na critica à economia política por Karl Marx e juntar a ele a contribuição de Georgescu-Roegen para examinar a crise ecológica tem conseqüências talvez ainda não completamente previsíveis para a renovação da teoria social. Poderia parecer à primeira vista que buscar os desdobramentos da produção industrial nos seus inevitáveis desdobramentos materiais, físicos (como em Georgescu-Roegen, que acentua a produção de dejetos) seria dar continuidade ao pensamento subjacente à critica de Marx à 
economia política no que diz respeito à apropriação da natureza. Para Marx, pelo menos naquilo que se deixa depreender do texto de $O$ Capital, a prática social (com suas representações, ideologias, ciência econômica etc.) apenas pode "processar a natureza" (reter suas determinações, elaborar, calcular) como categoria econômica: a "fertilidade natural” só é "vista" como "fertilidade econômica".

Num contexto de crise ecológica, quando a palavra chave é entropia (que GeorgescuRoegen liga a seus fenômenos correlatos como dejetos, radiação térmica, toxidade, ineficiência energética), pode-se dizer que Karl Marx, ao reproduzir conceitualmente a sociedade capitalista, tivesse retido "apenas" o esquema binário "produção-consumo": as classes sociais se definem (se "estabilizam” ou se reproduzem) na específica repartição do produto social possível sob a égide do capitalismo. A mais-valia (trabalho não pago ou sobre trabalho) se reparte pelas regularidades impostas pelas determinações formais de cada "setor": lucro para o industrial, juros para o banqueiro e renda fundiária para o proprietário da terra. A renda da terra resulta da propriedade privada de atributos naturais, mas estes são os atributos "consumíveis" que entram no circuito produção-consumo e não mostram a outra face: os dejetos.

Marx ao notar que os capitalistas já haviam se "territorializado", deixa entrever uma específica "produção" social da natureza em que se "legitima" uma das fontes dos ganhos capitalistas, quando a regulação do acesso à natureza se cumpre pelas categorias fundamentais próprias do capitalismo: concorrência, produtividade e preço. Isso quer dizer que este acesso à natureza se viabiliza apenas como uma projeção antropomórfica muito específica: selecionar da natureza os atributos que se "resolvem" como preço. Daí os insistentes ataques de Marx às recaídas empiristas dos economistas que relutavam em ver que é social o único modo de se "processar" a natureza. O problema agora surge quando "natureza" mostra a outra face não asseguradora de uma repartição "estabilizadora" dos produtos. Não se trata mais da já regulamentada luta pela repartição do produto a ser consumido (seja consumo ou improdutivo). Trata-se agora da degradação material e energética que se manifesta também como "natureza", mas só que agora não mais como fonte que assegura a distribuição "funcional" entre as classes sociais.

Algumas dessas considerações sobre temas que se encontram basicamente n`O Capital podem se estender para asserções mais difundidas do pensamento de Karl Marx. É flagrante no pensamento de Marx a afirmação da "materialidade" da vida social em contraposição ao idealismo que imperava na Alemanha no seu tempo. Embora retendo grande parte das 
conquistas intelectuais de Hegel - o que se patenteia, sobretudo no "método" de O Capital -, Marx recusa a idéia de um "espírito absoluto" que presidiria o desdobrar da História e contrapõe a ele a luta pelo domínio material como motor das transformações sociais. É o metabolismo do homem com a terra que, condicionado pelo acervo de recursos técnicos, promove a divisão social. Fica implícita, em Marx a esperança que se deposita nos avanços do conhecimento científico que, ao impulsionarem as "forças produtivas", farão eclodir os modos até então mais estáveis da "injusta" divisão do produto social. Para uma sociedade determinada, entra em questão a sua específica divisão de classes quando, no entender de Marx, as condições materiais para uma outra repartição do produto já estão presentes; ou, no jargão do marxismo, quando as forças produtivas entram em contradição com a divisão social do trabalho. Como sugerido acima, Marx não teria motivo para recusar a leitura do capitalismo pela dualidade produção-consumo e assim pensar que a produção, além de propiciar o consumo (produtivo e improdutivo) também produz dejetos (e os correlatos da entropia como radiação térmica, degradação energética, perda da biodiversidade). Diante disso fica para o marxismo a questão - irrecusável no contexto do debate sobre a crise ecológica - de como se estruturariam as classes sociais quando a produção não seria mais exclusivamente fonte de estabilização ou não poderia mais ser enaltecida por si só como garantia de um mundo melhor, anunciando para as classes hoje subalternas melhores resultados nesse metabolismo do homem com a natureza.

\section{REFERÊNCIAS BIBLIOGRÁFICAS}

ALTVATER, E. Ökologische und Ökonomische Modalitäten von Zeit und Raum. In: PROKLA - Probleme des Klassenkampfs. Berlin: 1987.

ALTVATER, E. Der Preis des Wohlstands. Münster: Westfälisches Dampfboot, 1992.

COVENEY, P. A Flecha do Tempo. São Paulo, 1993.

GEORGESCU-ROEGEN, N. The entropy law and the economic process. London: Harvard University Press, 1999.

HÉMERY, D. Uma História da Energia. Brasília: UNB, 1993.

MARX, K. Theorien über den Mehrwert. Berlin: Dietz Verlag, 1959.

MARX, K. Teorias de la Plusvalia. Buenos Aires: Editorial Cartago, 1975.

MARX, K. Elementos Fundamentales para la critica de la Economia Política (Grundrisse). México: Siglo Veintiuno, 1977.

MARX, K.. Das Kapital. Berlin: Dietz Verlag, 1981. 